\title{
Cervical Disc Arthroplasty Versus Anterior Cervical Discectomy and Fusion
}

\author{
AHMED A. ABDELKHALEK, M.D. and MOHAMED ALAA ELDIN THABIT, M.D. \\ The Department of Neurosurgery, Faculty of Medicine, Cairo University
}

\begin{abstract}
Background: The anterior cervical discectomy for cervical disc prolapse has been the work horse for ages and it works fine but the mechanical problems that follows is actually problematic hence the evolution of total disc replacement.
\end{abstract}

Aim of Study: The aim was to compare the efficacy and safety of arthroplasty using the artificial cervical disc with the standard Anterior Cervical Discectomy and Fusion (ACDF) for the management of cervical disc prolapse at single level.

Patients and Methods: Sixty patients were included and randomized to one of two groups: Investigational patients (30) underwent arthroplasty using a disc prosthesis, and a control group (30 patients) underwent ACDF with a cervical cage. Patients were assessed pre-operatively, immediate postoperative period and at six weeks, three months, six, twelve, eighteen and-twenty-four months postoperatively. Efficacy and safety outcomes were measured according to the Neck Disability Index (NDI), visual analogue score, gait disturbance, disc height, range of motion (arthroplasty group) or bony fusion (control group), complications, rate of second surgery, and neurological outcome. Overall outcome was considered successful according to four pivot criteria: (1): Improvement of post-operative NDI score more than fifteen points over the preoperative score, (2): Improved neurological presenting symptoms, (3): No serious complications caused by the prosthesis or by the surgical procedure, and (4): No resurgery needed (superimposed fixation, revision, or non-elective implant removal).

Results: The one year rate of overall outcome were ninety five percent for the arthroplasty group and eighty six percent for the control group, the arthroplasty group was better than the control group for the NDI score improvement. The percentage of patients experiencing any adverse effects was six percent in the arthroplasty group and eight percent in the control group, which were not statistically different. Radiographic success was achieved in 9 ninety five percent of the arthroplasty group (maintenance of range of motion without bony fusion) and one hundred percent of control patients (fusion).

Correspondence to: Dr. Ahmed A. Abdelkhalek, E-Mail: ahmedasem2008@ hotmail.com
Conclusions: Arthroplasty is as efficient and successful as ACDF for the management of cervical disc pathology.

Key Words: Cervical disc arthroplasty-Anterior cervical discectomy and fusion - Cervical cage-Artificial cervical disc-Adjacent segment disease.

\section{Introduction}

ANTERIOR Cervical Discectomy and Fusion (ACDF) is the gold standard surgery for cervical disc prolapse. Though this method insures radical disc removal for the desired level with very high success rate but it carries the risk of adjoining segment failure as a result of the altered cervical mechanics and diminished motion at the treated level [1-4] . Adjacent segment failure or adjacent level disease is the presence of a recent onset root affection or cord affection due to segmental disc pathology just adjacent to a previously fused segment. The incidence of adjoining segment failure is variable in long term follow-up in patients previously operated by ACDF [4-8]. The incidence of adjoining segment failure increases with multiple level ACDF more than single level ACDF as the compensatory mechanisms of the remaining healthy levels fail to withstand the increased loads. From this point forward the idea of dynamic disc implant emerged as an attempt to solve that problem and decrease its incidence [9-13]. Dynamic implants may provide an advantage over the standard ACDF which include: Decreased adjacent level abnormal loads, preserved segmental motion and better postoperative outcome (e.g. less neck pain) $[\mathbf{8 , 1 1 , 1 3 ]}$ The efficacy of these implants and whether it is used foe single or multiple level is still debatable though it is of increased popularity [11,13-15]

\section{Patients and Methods}

This was a prospective study including sixty Patients who were randomized to 1 of 2 groups: 
Investigational group (30) underwent arthroplasty using an artificial disc and control patients (30) underwent ACDF with a cervical PEEK cage. Patients were operated at Cairo University Hospitals from May 2016 till December 2018, they were evaluated pre-operatively, immediate post-operative period for improvement, complications and wounds, then at 6 weeks, 3, 6, 12, 18 and 24 months postoperatively.

\section{Inclusion criteria:}

Age range from 18 to 50 years, single level cervical disc disease, soft disc herniation. Exclusion criteria included: Age above 50 years, multiple level disc disease, recurrent cases or previous ACDF, cervical myelopathy, Ossified Posterior Longitudinal Ligament (OPLL) and advanced cervical spondylosis. Evaluation pf patients were done by full history taking, pain distribution and intensity, full examination and past history, occupational history and precise neurological examination. VAS for neck pain and brachialgia, scoring was done preoperatively using the 10 point scoring system with $0=$ no pain and $10=$ severe pain, the Neck Disability Index (NDI) was also used to assess the disability caused by the disease and its impact on patients daily activity, the score ranges from no disability (0) to totally disabled (5) and it strongly correlates to the vas score. Radiological assessment with plain radiographs for range of motion, presence of osteophytes-discs complexes, disc height and advanced spondylosis. MRI scans for diagnosis of the affected level, spinal compression, presence of soft disc or osteophytes and presence of OPLL. All patients were operated by the anterior approach, the target level is marked using C-arm, neck is extended with padding below shoulders to aid neck extension, transverse collar incision at the desired level, dissection and discectomy using the operative microscope, then either artificial disc or ACDF is done. Post-operatively patients were assessed clinically for any adverse effects (e.g. Neurological deficits), VAS and NDI were done immediate post and periodically with X-ray assessment at the same intervals, efficacy and safety outcomes were measured according to the Neck Disability Index (NDI), visual analogue score for axial pain and radiculopathy, disc height preservation, range of cervical motion (arthroplasty group) or fusion (control group), Adverse Events (AEs), additional surgeries, and neurological status. Treatment was considered successful when all four of the following standards were fulfilled: (1): 15 points improvement of the NDI over the pre-operative score, (2): Clinical patient improvement, (3): No serious complications caused by the implant and (4): No resurgery such as adjuvant fixation, revision, or emergency implant removal.

\section{Results}

From the sixty patients included in the study there was 53 males and seven females, age ranged from 18 to 50 years, forty-eight complained of neck pain $(80 \%)$, all cases had radiculopathy i.e. brachialgia, sensory deficits were present in seven cases $(11.6 \%)$ and one patient had motor deficit (hand grip weakness). The one year success rate was $95 \%$ for the arthroplasty group and $86 \%$ for the control group, the arthroplasty group was better than the control group for NDI outcome. The percent of complications for both groups were not statistically different (6.8 and 8 percent respectively). Radiographic success was achieved in $95.0 \%$ of the arthroplasty patients (maintenance of range of cervical motion without fusion) and $100 \%$ of the control patients (fusion). Complications included superficial wound infection ( 2 cases $3.3 \%$ ), sensory deficit in 24 cases (40\%) represented with numbness with only 8 cases it was persistent.
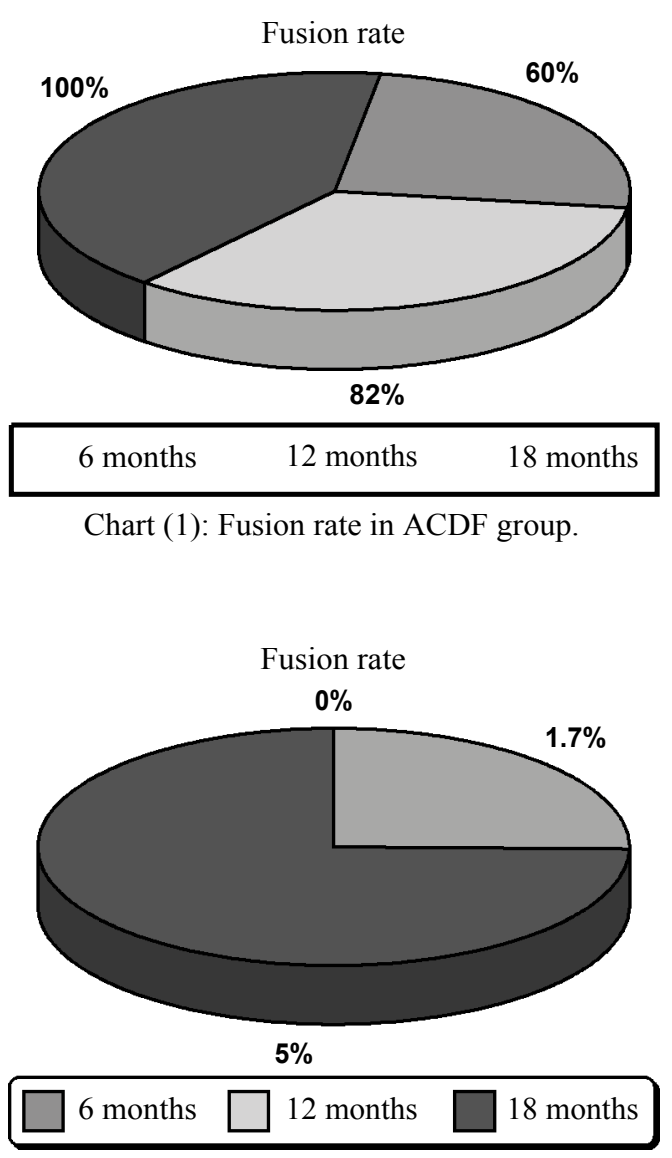

Chart (2): Fusion rate for the arthroplasty group. 

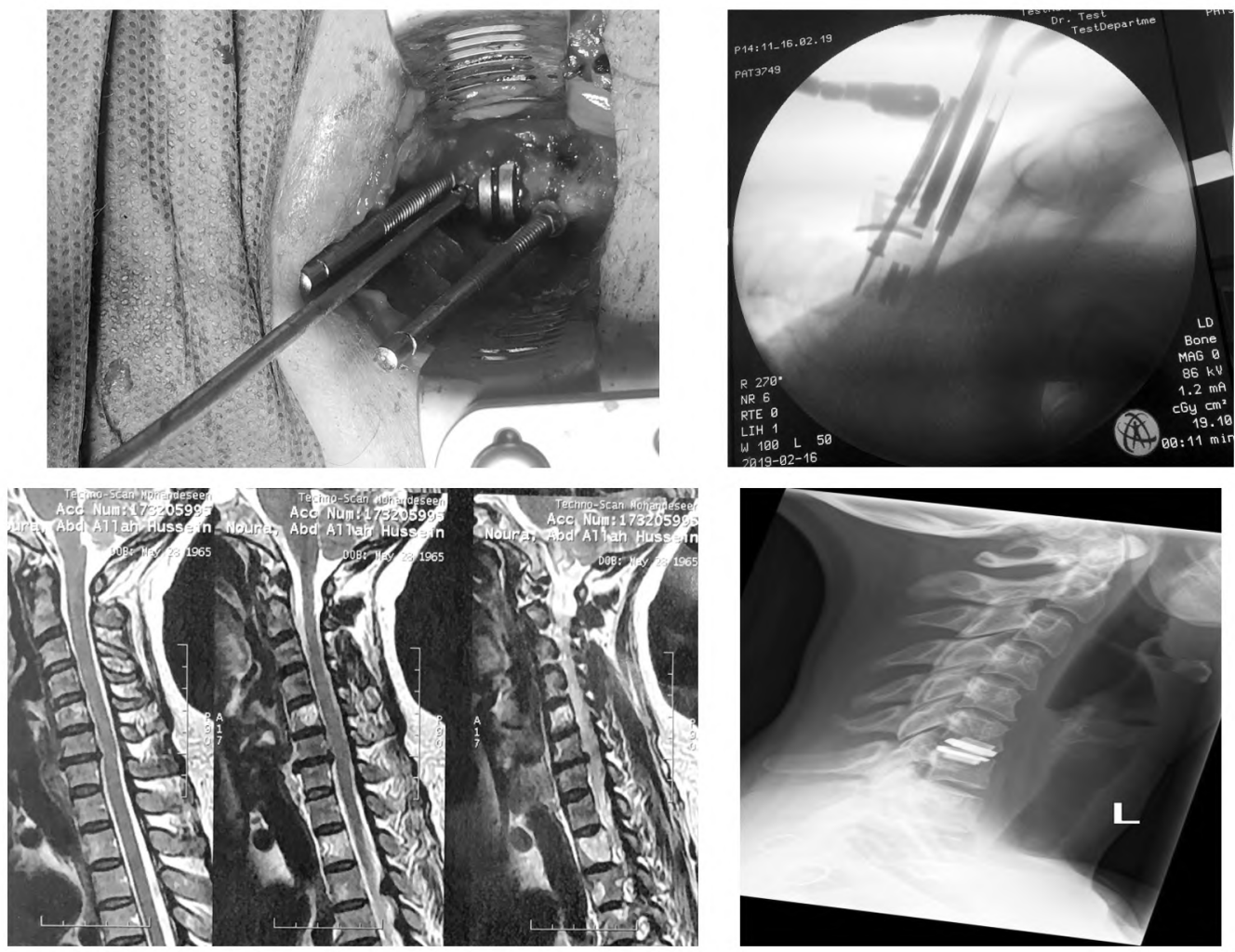

Fig. (1): A 37 year old male patient complained of right brachialgia operated by arthroplasty at C6/7 level.
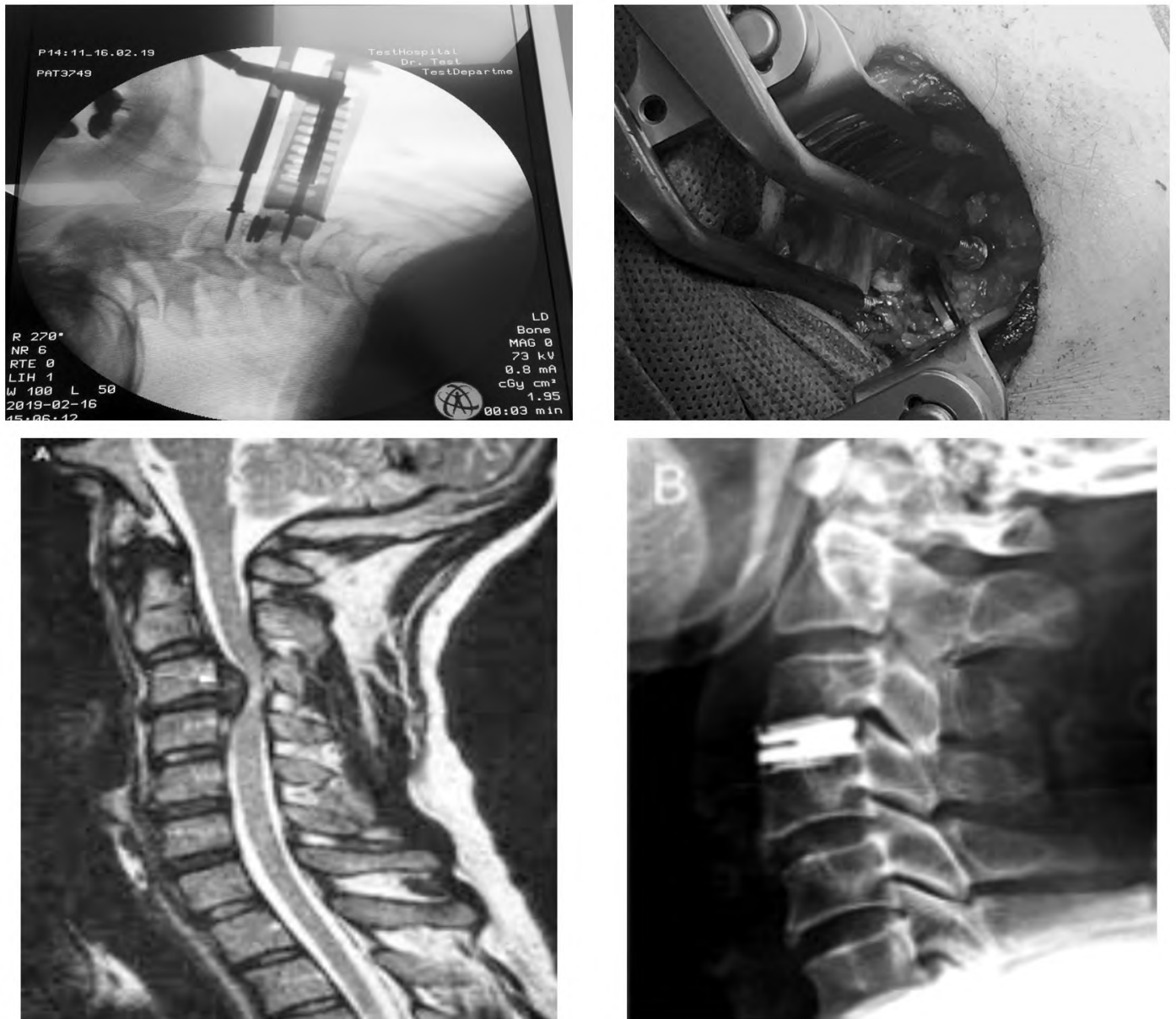

Fig. (2): A female patient with shoulder pain and myelopathy underwent 3/4 arthroplasty. 
Table (1): ACDF group with NDI score.

\begin{tabular}{lcccc}
\hline $\begin{array}{l}\text { NDI } \\
\text { score }\end{array}$ & $\begin{array}{c}\text { Pre- } \\
\text { operative }\end{array}$ & $\begin{array}{c}1.5 \\
\text { months }\end{array}$ & $\begin{array}{c}6 \\
\text { months }\end{array}$ & $\begin{array}{c}12 \\
\text { months }\end{array}$ \\
\hline Mild (5-14) & 10 & 12 & 18 & 8 \\
Moderate (15-24) & 12 & 10 & 8 & 4 \\
Severe $(>24)$ & 8 & 8 & 4 & 0 \\
\hline
\end{tabular}

Table (2): Arthroplasty group with NDI score.

\begin{tabular}{lcccc}
\hline $\begin{array}{l}\text { NDI } \\
\text { score }\end{array}$ & $\begin{array}{c}\text { Pre- } \\
\text { operative }\end{array}$ & $\begin{array}{c}1.5 \\
\text { months }\end{array}$ & $\begin{array}{c}6 \\
\text { months }\end{array}$ & $\begin{array}{c}12 \\
\text { months }\end{array}$ \\
\hline Mild & 12 & 18 & 12 & 8 \\
Moderate & 14 & 8 & 4 & 1 \\
Severe & 4 & 4 & 2 & 0 \\
\hline
\end{tabular}

Table (3): VAS score for neck pain in ACDF group.

\begin{tabular}{lccccc}
\hline \multicolumn{1}{c}{ Timing } & $\begin{array}{c}\text { Pre- } \\
\text { operative }\end{array}$ & $\begin{array}{c}1.5 \\
\text { months }\end{array}$ & $\begin{array}{c}6 \\
\text { months }\end{array}$ & $\begin{array}{c}1 \\
\text { year }\end{array}$ & $\begin{array}{c}18 \\
\text { months }\end{array}$ \\
\hline Low (1-3) & 2 & 4 & 12 & 16 & 18 \\
Moderate (4-6) & 24 & 18 & 12 & 11 & 11 \\
High (7-10) & 4 & 8 & 6 & 3 & 1 \\
\hline
\end{tabular}

Table (4): VAS score for neck pain in arthroplasty group.

\begin{tabular}{lccccc}
\hline \multicolumn{1}{c}{ Timing } & $\begin{array}{c}\text { Pre- } \\
\text { operative }\end{array}$ & $\begin{array}{c}1.5 \\
\text { months }\end{array}$ & $\begin{array}{c}6 \\
\text { months }\end{array}$ & $\begin{array}{c}1 \\
\text { year }\end{array}$ & $\begin{array}{c}18 \\
\text { months }\end{array}$ \\
\hline Low & 8 & 14 & 18 & 11 & 11 \\
Moderate & 16 & 12 & 10 & 4 & 2 \\
High & 6 & 4 & 2 & 0 & 0 \\
\hline
\end{tabular}

\section{Discussion}

In this study, we tried to clarify if there was a real benefit for the replacement of cage fusion with the arthroplasty device, is it worth it or not due to the financial brunt of the new technology in a developing country as Egypt which is an important issue. Though we couldn't address the problem of adjacent segment failure due to the short follow up period which was the main justification to shift to the arthroplasty device so we compared the neck disability, pain and fusion rate as these were also important factors for the patient and the outcome of the procedure.

In Several series, it was found that there were better neurologic outcomes with arthroplasty versus conventional anterior approach. Mummaneni et al., reported statistically significant neurologic improvement in patients undergoing arthroplasty using prestige ST cervical disc compared to $\mathrm{ACDF}$, in our study there was no difference regarding the neurological status and actually neurological improvement is dependent on the procedure not the prosthesis [22]. Heller et al., also showed statistically better improvement in NDI score, and overall outcome in patients who had surgery using Bryan cervical arthroplasty device versus ACDF [15] Also patients with arthroplasy returned to work an average of 2 weeks earlier than ACDF subjects, but there was no statistical discrepancy in the percentage of adjoining segment failure [15]. In our study the NDI score for the arthroplasty group were better at the 1.5 and six months period more than the ACDF group but at one year period it was almost the same which means that the arthroplasty group has better short term functional outcome. In another series, it showed no statistical significant discrepancy in neurologic outcomes, blood loss, surgical time, duration of hospital stay, NDI, VAS, or adjacent segment failure compared with ACDF patients [9].

In our study the VAS score for neck pain was by far better for the arthroplasty group than the ACDF with shorter period to return to work or normal activity.

Gore and Sepic included 50 patients in their work following them up for up to 21 years following ACDF, [13] forty-eight of them had new disc disease findings on radiographic scans, but only eight needed re-surgery due to the presence of significant radiculopathy, or cord compression signs. Baba et al., in their series followed-up over one hundred patients (106), 42 had one-level fusion, 52 with double level fusion, twelve had three-level fusion) for up to 8.5 years, [3] adjoining segment failure occurred at $39 \%$ rate which was a significant rate. Herkowitz et al., had incidence of $41 \%$ adjacent segment failure following single level ACDF [16].

The present data can't yet prove or deny if arthroplasty will diminish or erase the risk of adjacent segment disease. the follow-up periods utilized up till now didn't raise enough long-term evidence to clarify this important issue. Recently Nunley et al., examined the outcomes of patients that were included in five different cervical arthroplasty trials with follow-up period from 4 to 7 years they showed a $2.3 \%$ rate of clinically symptomatic adjoining segment disease [17]. While Murrey et al., produced data that there was no whatsoever statistical discrepancy between ACDF and arthroplasty in the issue of adjacent segment failure.

Adjacent to cervical fusion, pressure inside the disc increases by approximately $50 \%$ in the contiguous adjacent segment and $125 \%$ in the other 
distal levels [18]. When comparing arthroplasty to conventional ACDF, most studies with follow-up periods of two years or more did not find any significant difference concerning adjoining segment failure [19,20]. A study by Coric et al., [21] did find a significant increase in adjacent segment failure in their series on single level disc disease operated by ACDF compared to the single level arthroplasty group, at 2-year follow-up. Dang et al., [22] stated there was significant increase in adjacent segment failure after double level fusion compared to single level fusion.

Fay et al., [23] studied the differences between arthroplasty and ACDF in double level degenerative disease. Cervical arthroplasty preserved the range of motion at the operated levels and gave similar clinical results as ACDF at nearly 40 months follow-up intervals after surgery [23]. In a prospective randomized study at several centers double level artificial disc replacement with the Mobi-C cervical artificial disc against ACDF, four year results clarified a significantly higher improvement in the NDI scores, patient content, and overall better outcome in the arthroplasty group. Also the ACDF patients had a higher incidence of second surgery (15.2\% vs. $4 \%)$ and radiographic adjacent segment failure [23]. also the incidence of radiographic disc disease was found to be $86 \%$ in the ACDF group compared with $42 \%$ in the arthroplasty group [23] davis RJ et al., used the Mobi-C disc prosthesis in patients and stated that it maintained the segmental range of motion for a follow-up period of 48 months. Similarly Radcliff et al., in a multiple center study reported a significantly higher improvement in NDI scores, shorter hospital stay, and better patient satisfaction at five year followup in patients treated with a 2-level arthroplasty compared to a double level ACDF [24]. Moreover, the resurgery incidence in this study was much lower for the arthroplasty group (4\%) in comparison to the ACDF group (16\%) at the target level, and at adjacent levels (3. $1 \%$ vs. $11.4 \%$ ) [24].

\section{Conclusion:}

Arthroplasty is superior to ACDF in outcome regarding NDI and VAS scoring systems but regarding adjacent segment failure needs long term period of follow-up with the same adverse effects for both procedures.

\section{References}

1- ANDERSON P.A., SASSO R.C. and RIEW K.D.: Comparison of adverse events between the Bryan artificial cervical disc and anterior cervical arthrodesis. Spine, 33: 1305-12, 2008.
2- AGRILLO U., FACCIOLI F., FACHINETTI P., GAMBARDELLA G., GUIZZARDI G. and PROFETA G. Guidelines for the diagnosis and management of the degenerative diseases of the cervical spine. J. Neurol. Sci., 43: 11-4, 1999.

3- BABA H., FURUSAWA N., IMURA S., KAWAHARA N., TSUCHIYA H. and TOMITA K.: Late radiographic findings after anterior cervical fusion for spondylotic myeloradiculopathy. Spine, 18: 2167-73, 1993.

4- BOHLMAN H.H., EMERY S.E, GOODFELLOW D.B. and JONES P.K. : Robinson anterior cervical discectomy and arthrodesis for cervical radiculopathy. Long-term follow-up of one hundred and twenty-two patients. J. Bone. Joint. Surg. Am., 75: 1298-307, 1993.

5- BRODKE D.S. and ZDEBLICK T.A. : Modified SmithRobinson procedure for anterior cervical discectomy and fusion. Spine, 17: S427-30, 1992.

6- CAO J.M., ZHANG Y.Z., SHEN Y., XU J.X., DING W.Y., YANG D.L., et al.: Clinical and radiological outcomes of modified techniques in Bryan cervical disc arthroplasty. J. Clin. Neurocsci., 18: 1308-12, 2011.

7- CAVANAUGH D.A., NUNLEY P.D., KERR E.J., 3 rd WERNER D.J. and JAWAHAR A.: A delayed hypersensitivity to metal ions after cervical disc arthroplasty. Spine, 34: 262-5, 2009.

8- CHEN J., WANG X., BAI W., SHEN X. and YUAN W. Prevalence of heterotopic ossification after cervical total disc arthroplasty: A meta-analysis. Eur. Spine. J., 21: 67480, 2012.

9- CORIC D., NUNLEY P.D. and GUYER R.D.: Prospective, randomized, multicenter study of cervical arthroplasty: 269 patients from the Kineflex C artificial disc investigational device exemption study with a minimum 2-year follow-up: Clinical article. J. Neurosurg. Spine, 15: 34858, 2011.

10- DATTA J.C., JANSSEN M.E., BECKHAM R. and PONCE C.: Sagittal split fractures in multilevel cervical arthroplasty using a keeled prosthesis. J. Spinal. Disord. Tech., 20: 89-92, 2007.

11- GOFFIN J., VAN CALENBERGH F., VAN LOON J., CASEY A., KEHR P., LIEBIG K., et al.: Intermediate follow-up after treatment of degenerative disc disease with the Bryan cervical disc prosthesis: Single-level and bi-level. Spine, 28: 2673-8, 2003.

12- GOFFIN J.: Complications of cervical disc arthroplasty. Semin. Spine Surg., 18: 87-97, 2006.

13- GORE D.R., SEPIC S.B. and GARDNER G.M.: Neck pain: A long-term follow-up of 205 patients. Spine, 12: $1-5,1987$.

14- GUYER R.D., SHELLOCK J., MACLENNAN B., HANSCOM D., KNIGHT R.Q., MCCOMBE P., et al.: Early failure of metal-on-metal artificial disc prostheses associated with lymphocytic reaction: Diagnosis and treatment experience in four cases. Spine, 36: E492-7, 2011.

15- HELLER J.G., SASSO R.C., PAPADOPOULOS S.M., ANDERSON P.A., FESSLER R.G., HACKER R.J., et al.: Comparison of the BRYAN cervical disc arthroplasty with anterior cervical decompression and fusion: Clinical and radiographic results of a randomized, controlled, clinical trial. Spine, 34: 101-7, 2009. 
16-HERKOWITZ H., KURZ L. and OVERHOLT D.: Surgica management of cervical soft disc herniation: A comparison between the anterior and posterior approach. Spine, 15: 1026-30, 1990.

17- NUNLEY P.D., CORIC D., JAWAHAR A., KERR E.J., GORDON C., UTTER P.A., et al.: Total Disc Replacement in Cervical Spine: 4-7 years follow-up for primary outcomes and symptomatic adjacent segment disease. Cervical. Spine. Res. Soc., 2011.

18- DMITRIEV A.E., CUNNINGHAM B.W., HU N., SELL G., VIGNA F. and MCAFEE P.C.: Adjacent level intradiscal pressure and segmental kinematics following a cervical total disc arthroplasty: An in vitro human cadaveric model. Spine (Phila Pa 1976), 30: 1165-72, 2005.

19- NUNLEY P.D., JAWAHAR A., KERR E.J. $3^{\text {rd }}$, et al.: Factors affecting the incidence of symptomatic adjacentlevel disease in cervical spine after total disc arthroplasty: 2-to 4-year follow-up of 3 prospective randomized trials. Spine (Phila Pa 1976), 37: 445-51, 2012.

20- MALDONADO C.V., PAZ R.D. and MARTIN C.B.: Adjacent-level degeneration after cervical disc arthroplasty versus fusion. Eur. Spine. J., 20 (suppl 3): S403-S7, 2011.
21- CORIC D., NUNLEY P.D., GUYER R.D., et al.: Prospective, randomized, multicenter study of cervical arthroplasty: 269 patients from the Kineflex|C artificial disc investigational device exemption study with a minimum 2-year follow-up: Clinical article. J. Neurosurg. Spine, 15: 348-58, 2011.

22- DANG A.B.C., HU S.S. and TAY B.K.B.: Biomechanics of the anterior longitudinal ligament during $8 \mathrm{~g}$ whiplash simulation following single- and contiguous two-level fusion: A finite element study. Spine. (Phila Pa 1976), 33: 607-11, 2008.

23- FAY L.Y., HUANG W.C., TSAI T.Y., et al.: Differences between arthroplasty and anterior cervical fusion in twolevel cervical degenerative disc disease. Eur. Spine. J., 23: 627-34, 2014.

24- RADCLIFF K., CORIC D. and ALBERT T.: Five-year clinical results of cervical total disc replacement compared with anterior discectomy and fusion for treatment of 2 level symptomatic degenerative disc disease: A prospective, randomized, controlled, multicenter investigational device exemption clinical trial. 25: 213-24, 2016.

\title{
مقارنة بين الغضروف العنقى الأصطناعى والإندماج القفصى من العنمئ

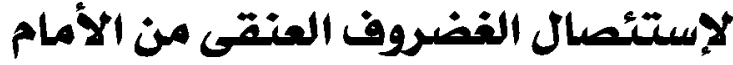

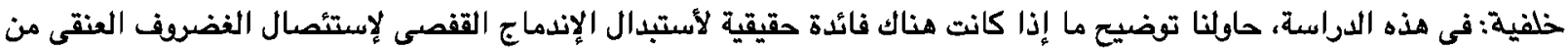

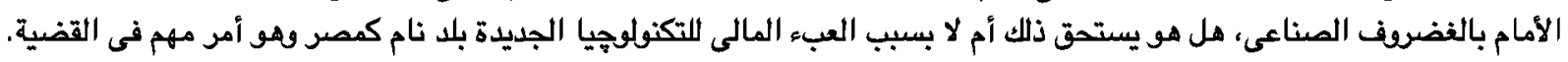 \\ الهدف من الدراسةة: على الرغم من أنتا لم نتمكن من معالجة مشكلة فشل الجزء المجاود بسبب فترة المتابعة القصيرة التى كانت المبرد

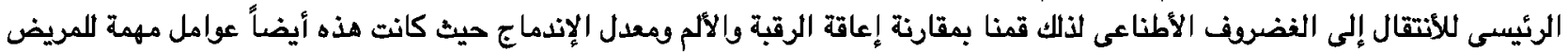 \\ ونتائج الإجراءات التى تمت المريض.

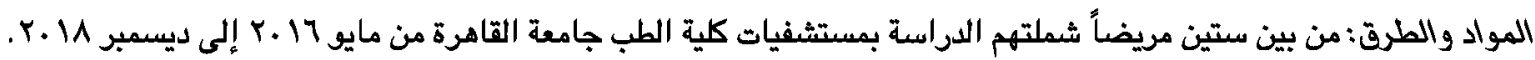

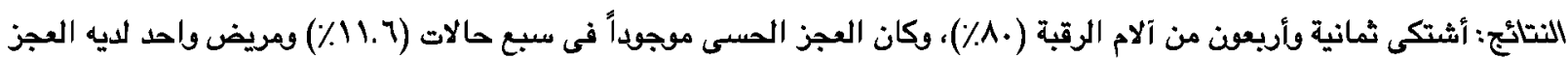

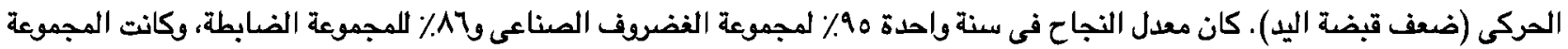 \\ الأولى أفضل من المجموعة الضابطة لنتائج إعاقة الرقبة. \\ الخلاصة: ولذلك يحتاج الأمر إلى دراسة مطولة أكثر وعدد أكثر من المرضى المتابعة وتقرير مدى كفاءة الغضاريف الصناعية.
}

